\title{
American Pediatric Society Presidential Address 1993: The Fetal Frontier
}

\author{
DELBERT A. FISHER
}

Nichols Institute, San Juan Capistrano, (alifornia 92690)

As presidents before me have recognized. one of the privileges of this office is the opportunity of addressing you as a partially captive audience with a subject of my choice. These presidential addresses usually have focused on one or another current problem or progress area of our academic pediatric endeavors and usually have reflected the personal interest or expertise of the then-president. I will follow that pattern. My interests and research during the past 40 years have been developmental endocrinology and metabolism, heavily oriented to animal models and the laboratory bench. My trainees have been endocrinologists, adult and pediatric, with a recent trend to neonatologists and obstetricians. My collaborators have been fellow pediatricians and internists, as well as obstetricians and $\mathrm{PhD}$ basic scientists. My clinical base has been endocrinology and metabolism with secondary involvement in general pediatrics, perinatal medicine, and neonatology. In addition. I have been privileged to serve as a journal editor and as a department chair.

From these vantage points over the past 40 years, I have witnessed the incredible changes in most areas of our discipline and in medicine in general. Highlights include the following: control of childhood contagion, ability to image internal organs, major advances in the war on cancer, routine organ transplantation, ability to build proteins and antibodies to specification. evolution of molecule-directed therapeutics, and ability to construct and transfect genes. However, the area of most impressive progress in clinical pediatrics during the past two decades has been neonatal-perinatal medicine. The growth of this clinical subspecialty has been extraordinary, with a profound impact on our relationship with obstetricians, the structure and funding of our academic pediatric departments, and the structure and content of our annual APS-SPR meetings. The successes of the enterprise are obvious to all. My intent today is to trace briefly the evolution of perinatal medicine and focus on the still-evolving frontier.

Fetal and perinatal medicine are relatively new fields. During the first half of the 20th century, there was little attention to fetal physiology. William Windle in his preface to Physiology' of the Fetus, published in 1940, commented, ". . .[A]fter initial exploration of the field (in the late 19th century), physiologists turned their attention to more urgent problems concerning the adult" (1). That inattention lasted nearly half a century. Ashley Weech, in his forward to Physiology of the Perinatal Period, edited by Uwe Stave in 1970, wrote, "Not so many years ago, problems surrounding the fetus and newly born infant lay in a realm almost to be described as 'a no-man's land' (2).

This situation began to change during the 1930s when Joseph Barcroft in England and other pioneers began to study fetal physiology in animal models. By the time of World War II, there had been considerable progress in the areas of placental function and fetal cardiovascular-respiratory physiology. This progress was documented by the then-Sir Joseph Barcroft in his book "Researches on Pre-Natal Life, which was published by Blackwell Scientific Publications in Oxford in 1946, just before Professor Barcroft's death in 1947 (3). Of interest, the literature at the time was such that Dr. Barcroft dealt with it as a single author.
World War II interrupted this early progress, but during the 1950 s there was a resurgence of interest in fetal physiology and development, aided and abetted by a variety of medical and technologic advances during the war years. These advances included improved surgical methods and procedures, more effective anesthetics, intravenous fluids, blood preservation techniques, and antibiotics. New analytical methods included flame photometry, new blood chemistry techniques, improved chromatography methods, physiologic recorders, radioisotopes, and, perhaps most importantly, there was National Institutes of Health support for basic and clinical biomedical research in the United States. Rapid progress ensued, and by the 1970s this progress was manifest in numerous national and international meetings and in multiauthor texts focused on fetal and perinatal physiology.

This basic scientific progress gradually stimulated clinical interest. Ashley Weech went on to say, "Within little more than a score of years, the (no man's land) picture changed. Obstetricians led by Nicholson Eastman, pediatricians guided by Clement Smith, pathologists represented by Sydney Farber and Edith Potter, the anesthesiologist Virginia Apgar, and many others recognized the reward to be gained by exploring a previously neglected field" (2).

As all of us are aware, the neglect has been largely corrected: the current size and scope of the clinical perinatal enterprise is indeed impressive. One has only to review the proceedings of our APS-SPR meetings to document this. Table 1 summarizes the growth in number and percent of neonatal abstracts and in neonatal subject-oriented oral sessions at the annual APS-SPR meetings during the past 20 years. Published neonatal abstracts increased 12-fold, from 69 in 1972 to 820 in 1992. This represented an increase from about $10 \%$ to $38 \%$ of total published abstracts. Oral presentations increased from two general neonatology sessions to a total of eight general and subspecialty neonatal sessions. Additionally, a number of new societies oriented to fetal and neonatal medicine, several journals focused on developmental biology, and newer sections of older societies highlighting perinatal and developmental topics have evolved to provide for dissemination of an ever-expanding volume of data dealing with developmental physiology and perinatal medicine.

Progress in clinical neonatology has been importantly linked to progress in basic fetal and perinatal research. The expanding knowledge base has directly improved the effectiveness of our neonatal intensive care units. The survival and quality of life of our premature infants in these units has improved continually and has extended to progressively smaller, more immature infants (4-6). However, we are approaching a limit to the practical extrauterine care of very immature fetuses. These approaching limits are the result of progressive fetal system immaturities and delayed extrauterine adaptations as gestational age decreases.

The net effect of these immaturities is reflected in survival and in persisting functional deficits. Survival is illustrated in Figure 1 , which plots percent survival versus weeks of completed gestation. These data were compiled by Jeffrey Pomerance at the Cedars Sinai Medical Center in Los Angeles and show published 
Table 1. Growth of neonatal sections of APS-SPR annual meetings between 1972 and 1992*

\begin{tabular}{cccc}
\hline Year & $\begin{array}{c}\text { No. neonatal } \\
\text { abstracts }\end{array}$ & $\begin{array}{c}\text { Neonatal/total } \\
\text { abstracts }\end{array}$ & $\begin{array}{c}\text { No. neonatal } \\
\text { oral sessions }\end{array}$ \\
\hline 1972 & 69 & $11 \%$ & 2 \\
1977 & 94 & $8 \%$ & 2 \\
1981 & 252 & $14 \%$ & 3 \\
1987 & 711 & $36 \%$ & 8 \\
1992 & 820 & $38 \%$ & 8 \\
\hline
\end{tabular}

* Data from program and abstracts published yearly in Pediatric Research

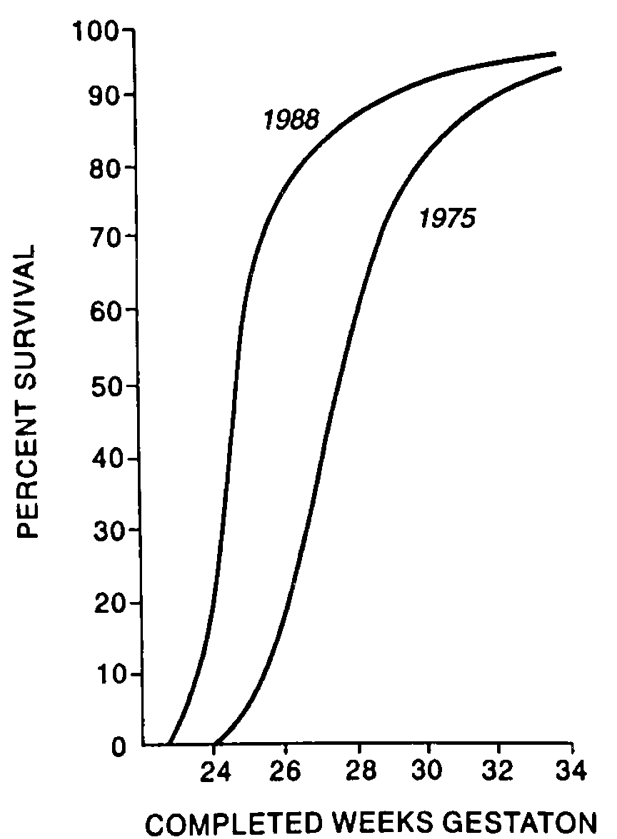

Fig. 1. Smoothed neonatal survival rate at Cedars Sinai Medical Center. 1975 and 1988. Infants who never left the hospital alive, regardless of time of death, were considered neonatal deaths. Data from reference 7 and personal communication.

data for 1975 and unpublished data for 1988 (7; personal communication). Survival in 1975 fell off rapidly below 30 weeks. The plot was shifted to the left by 2 to 3 weeks by 1988, but the threshold of viability was minimally impacted. The accrued deficits are more difficult to quantify. We reduce them in the upper range of the curve and accrue them in the ever more immature infants as we extend our technology.

By analogy with flight, we learned to fly since the Wright brothers taught us, and we developed some sophisticated machines. But then came the sound barrier. In fetal medicine, we now approach the second trimester, the fetal frontier. The fetal intrauterine environment differs significantly from that in infancy or childhood. This certainly is true for the endocrine metabolic systems for which I have most insight. The fetal endocrine milieu has evolved to encompass a variety of strategies to support the maturation and extraordinary growth rate of the mammalian fetus in the intrauterine environment (8). These strategies include several unique and transient endocrine organs including the placenta, the fetal adrenal cortex, the paraaortic chromaffin system, and the intermediate pituitary gland. A variety of predominantly fetal hormones embelish the fetal milieu, including antimullerian hormone, arginine vasotocin, calcitonin, parathyroid hormone-related protein, and a growing spectrum of peptides and growth factors.

In this fetal milieu, the placenta is most remarkable (8). This critical organ transports the substrates and excretes the waste products supporting the programmed, genetically determined growth and maturation of the parasitic fetus. It also serves as an auxiliary master endocrine gland as indicated in Figure 2. As suggested by this cartoon, the endocrine placenta produces a staggering variety of hormones including the pituitary-like hormones, placental lactogen and chorionic gonadotropin, a full complement of hypothalamic releasing hormones, large amounts of progesterone and estrogens, and a wide variety of growth factors and other regulatory proteins. Our understanding of the roles and interactions of these hormones and growth factors in maternal and fetal metabolism remains unclear, but it is likely that they are particularly important to the immature fetus, which has not yet developed autonomous control of its complex metabolic processes. Removal of these auxiliary controls before midgestation creates a formidable support problem for the immature fetus in the extrauterine environment.

In fact, a variety of complex extrauterine adaptations involving many systems are involved in successful extrauterine survival. The fetal thyroid system, for example, is not essential for fetal growth and development. However, it is critically important for growth and development and thermogenesis in infants and children. Although the fetal hypothalamic-pituitary-thyroid system develops largely autonomously of the maternal system, there is limited fetal system function during early pregnancy. By midgestation, the human fetus is producing significant amounts of thyroid hormones, and there is progressive maturation of thyroid hormone production and control during the latter half of gestation. Even during late gestation, however, metabolism of thyroid hormones differs markedly in the fetus from that postnatally as shown in Figure 3.

During childhood, thyroxine $\left(\mathrm{T}_{4}\right)$ is a prohormone that is converted to the active hormone triiodothyronine $\left(\mathrm{T}_{3}\right)$ by a monodeiodinating enzyme in peripheral tissues. This active $T_{3}$ stimulates thermogenesis and is required for normal growth and development. In the fetus, activity of the enzyme, referred to as type I iodothyronine monodeiodinase, is quite low. As a result, there is limited conversion of $T_{4}$ to the active hormone $T_{3}$ and circulating levels of $T_{3}$ are quite low in the fetus $(8,9)$. Increased activity of another monodeiodinase enzyme in the fetus converts $\mathrm{T}_{4}$ to the inactive metabolite reverse triiodothyronine ( $\mathrm{rT}_{3}$ ). Sulfation of thyroid hormones in the fetus also is increased. As a result, the major circulating thyroid hormone metabolites in the fetus are biologically inactive $\mathrm{rT}_{3}$ and the sulfated conjugates of $T_{4}, T_{3}$, and $r T_{3}$, which also are biologically inactive (9). Additionally, because the hypothalamic pituitary axis is progressively immature before 32 weeks' gestation, small premature infants are born with a state of hypothalamic or tertiary hypo-

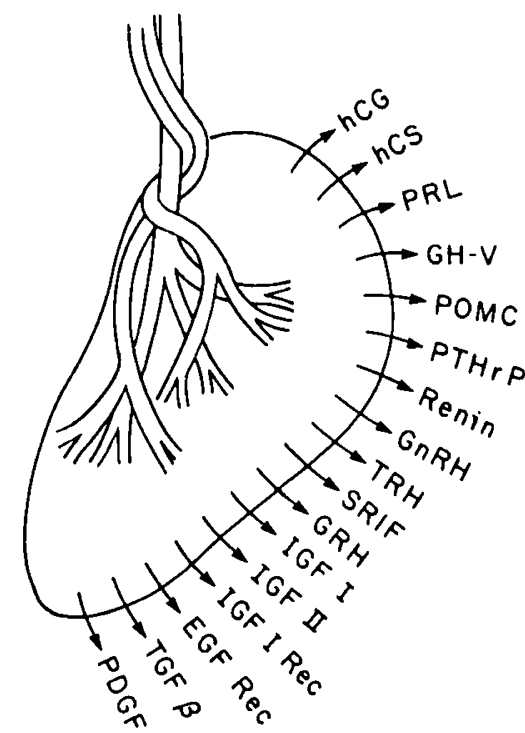

Fig. 2. Hormones known to be produced by the human placenta This is a partial listing, increasing yearly. 


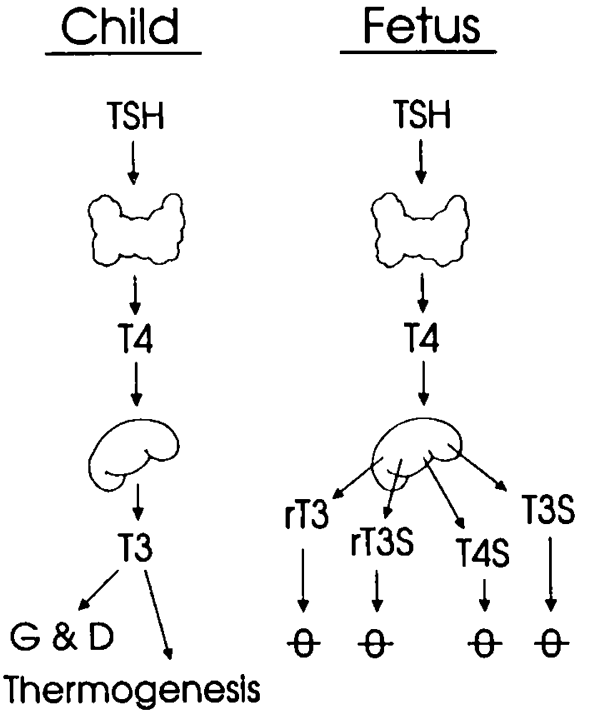

Fig. 3. General pattern of thyroid hormone production and metabolism in children and in the third-trimester fetus. See text for details.
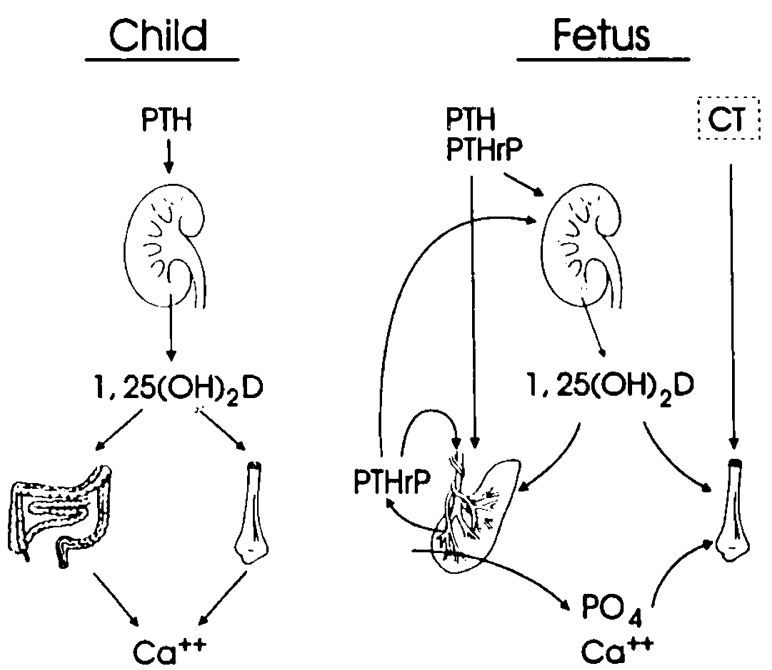

Fig. 4. General pattern of calcium flux and control in children and in the third-trimester fetus. CT. calcitonin. See text for details.

thyroidism. These immaturities and the pathways for thyroid hormone metabolism in the small premature infant require several weeks to mature to the extrauterine environment.

Another example of unique fetal endocrine physiology and complex extrauterine adaptation is the parathyroid-hormonevitamin D system for regulation of calcium-phosphorus absorption and metabolism. This is summarized in Figure 4. As noted in the Figure 4, parathyroid hormone (PTH) secreted from the parathyroid gland during childhood acts on the kidney to hydroxylate $25-\mathrm{OH}$ vitamin $\mathrm{D}$ to bioactive $1,25(\mathrm{OH})_{2} \mathrm{D}$, which then acts on the gut to increase calcium absorption and on bones to support mineralization. In the fetus, a different gene product, PTH-related protein (PTHrP), is produced by the parathyroid glands and the placenta (8). PTHrP, like PTH in the adult, appears to stimulate $1,25(\mathrm{OH})_{2} \mathrm{D}$ production by the fetal kidney. PTHrP and $1,25(\mathrm{OH})_{2} \mathrm{D}$ also appear to act on the placenta to stimulate active maternal to fetal placental transport of calcium and phosphorus to provide substrate for fetal bone mineralization. Calcitonin is a largely vestigial hormone in childhood or adulthood. The fetus, in contrast, manifests high circulating levels of calcitonin that tend to inhibit mobilization of bone calcium and augment bone anabolism in support of rapid intrauterine skeletal growth. This complex system is disrupted with cord clamping, and autonomous regulation of serum calcium becomes essential. The transition of this system to the extrauterine mode is progressively delayed with increasing prematurity.

There are many more examples of immaturities and complex metabolic transitions of premature infants that each subspecialty group could compile. Understanding these and providing support during the transition and early extrauterine period has lowered progressively the gestation age and size compatible with extrauterine survival. There is an increasing volume of papers documenting survival of increasingly immature fetuses. Critics point out, however, that the prevalence of residual impairments remains high. The human, family, community, and economic costs of this effort have become the subject of increasingly intense debate. William Silverman in the December issue of Pediatrics contributed an article entitled "Overtreatment of Neonates? A Personal Perspective" (10). There is, he writes, "a pervasive suspicion that overtreatment of seriously compromised neonates is now widespread in this country." It is not my intent to engage in that debate. The controversy exists. It is the price of progress and the debate will continue, as will progress in neonatal intensive care.

But how do we attack this formidable new frontier? There are several ongoing strategic initiatives. These place increasing emphasis on alternative and supplemental approaches to neonatal intensive care. We are not going to develop an artificial uteroplacental unit in the near future. Vigorous current efforts are focused on the reduction in prevalence of prematurity. There has been increasing emphasis on provision of prenatal care to disadvantaged women to accomplish this goal. Effective medical care for pregnant women must be a national priority. Our pediatric and obstetric communities have been inscribing this message on the political agenda, and movement in this direction is slowly being made (11). Our obstetric colleagues continue their efforts to understand and neutralize the mechanisms of premature labor, and there will be near-term progress in this area.

There is, in addition, another approach that Dr. Shoichi Sakamoto refers to as direct fetal medicine. Dr. Sakamoto in his presidential address to the First International Congress of Perinatal Medicine in Tokyo in 1991 characterized three eras of fetal medicine (12) (Table 2).

The first period, 1965-75, he referred to as the era of fetal emergency care; the second period, 1975-85, he called the era of long-term management of abnormal fetuses during pregnancy; the current era he refers to as the period of individual fetal diagnosis and management. Fetal emergency care was made possible in the late 1960 s by new technology for fetal monitoring. particularly cardiotacography and acid-base monitoring. In addition, a number of placental hormone tests were applied to the assessment of placental function. This era focused attention on the immediate extrauterine transitional problems and codified important management principles.

The era of long-term management evolved with the availability of ultrasound and Doppler ultrasound, amniocentesis, chorionic villus sampling, placental biopsy, intrauterine blood transfusion, the evolution of direct fetal surgical approaches, and maternal treatments to manage fetal problems transplacentally. This has been a largely entreprenurial and exploratory effort that has paved the way for more substantive advances. The emerging era of individual fetal management will extend to the 21 st century. We can expect continuing improvements in ultrasound technology for fetal visualization and fetal cord blood sampling for fetal

Table 2. The eras of fetal medicine-Shiochi Sakamoto, 1991

$\begin{array}{cc}1965-75 & \begin{array}{l}\text { Fetal emergency care } \\ 1975-85\end{array} \\ & \begin{array}{c}\text { Long-term manage- } \\ \text { ment of abnormal } \\ \text { fetuses in utero } \\ \text { Individual diagnosis: } \\ \text { therapeutic devices }\end{array}\end{array}$


diagnosis. Improvements in fetal surgery will expand the spectrum of anomalies and fetal disorders amenable to surgical repair or amelioration. Chronic fetal infusion therapy is ongoing in animal models and will be adapted to human use. Methods for isolating nucleated fetal cells from maternal blood are in process of development. Gene therapy for adenosine deaminase deficiency in the newborn has been reported recently in the lay press. Molecular diagnosis is now possible using polymerase chain reaction and fetal cells, and gene therapy will be extended to the in utero fetus as this approach is developed for routine use.

Individual fetal therapy already has been applied to a variety of fetal diseases. Table 3 lists the fetal anomalies that pioneering surgeons have approached via transuterine fetal surgery $(13,14)$. Anomalies managed to date include: urethral obstruction, diaphragmatic hernia, chylothorax, sacrococcygeal teratoma, and cystic adenomatoid lung. Fetal liver transplantation has been ongoing for more than a decade (14). Healing of the fetal wounds is rapid and tends to occur with minimal scarring (15). Table 4 lists examples of the fetal disorders that have been managed by maternal or direct fetal drug therapy $(14,16)$. Among these are congenital adrenal hyperplasia, agammaglobulinemia and idiopathic thrombocytopenic purpura, maternal diabetes with fetal hyperglycemia and hyperinsulinism, hyper- and hypothyroidism, fetal cardiac arrhythmias, and vitamin-responsive metabolic disorders including methylmalonic aciduria, $\mathrm{B}_{12}$ responsive mega-

Table 3. Fetal anomalies managed surgically

Urethral obstruction

Diaphragmatic hernia

Chylothorax

Sacrococcygeal teratoma

Cystic adenomatoid lung

Table 4. Fetal disorders amenable to medical treatment

Adrenal hyperplasia

Agammaglobulinemia

Diabetes-fetal hyperglycemia

Hyperthyroidism

Hypothyroidism

Idiopathic thrombocytopenic purpura

Fetal arrhythmias

Vitamin responsive metabolic disorders

Methylmalonic aciduria

$B_{12}$-responsive megaloblastic anemia

Biotin-responsive multiple carboxylase deficiency

Table 5. Fetal medicine: a team effort

Perinatologists
Maternal fetal medicine specialist
Neonatologist
Subspecialists
Cardiologist
Endocrinologist
Gastroenterologist
Geneticist
Infectious disease specialist
Nephrologist
Neurologist
Support specialists
Laboratory
Nurse specialist
Imaging expert

loblastic anemia, and biotin-responsive multiple carboxylase deficiency.

The diagnosis and management of such disorders clearly requires a team effort (Table 5). Logically the team would be composed of perinatologists, including maternal fetal medicine specialists and neonatologists; they will also need trained paramedical support personnel. A variety of subspecialist consultants with the necessary technologic and organ focus will provide expertise to deal with the individual problem or problems encountered. As with cardiac surgery teams, these fetal therapy teams would be developed in major medical centers where collaborative subspecialty efforts can be developed and routinized. Experienced and efficient fetal visualization and monitoring are essential ingredients to team success. As individualized fetal therapy becomes more routine, the less-invasive procedures will be progressively incorporated into general obstetric practice; here, too, collaborative efforts of neonatologists, geneticists, and other selected subspecialists will be important.

Would this be cost effective? Dr. Jeffrey Pomerance in 1980 pointed out the dramatically lower cost of intrauterine maintenance of the fetus, which he referred to as "womb rent," relative to the cost neonatal intensive care unit care (7). Using his approach, we can estimate a cost in the range of $\$ 50$ to $\$ 100$ per hour for every womb hour salvaged for small premature infants relative to the cost of bed rental in the neonatal intensive care unit.

The role of the neonatologist in this evolving era remains to be defined. A truly collaborative approach with the maternalfetal medicine specialists would seem optimal. The present generation of neonatologists has the opportunity to develop such a relationship and to define that role. We applaud their accomplishments to date and wish them continued success in extending the frontier. We await the future with high expectations.

\section{REFERENCES}

1. Windle WF 1940 Physiology of the Fetus. WB Saunders. Philadelphia

2. Stave U 1970 Physiology of the Perinatal Period. Appleton Century Crofts, New York

3. Barcroft Sir J 1946 Researches on Pre-Natal Life. Blackwell Scientific Publications, Oxford. UK

4. Grogaard JB, Lindstrom DP. Parker RA. Culley B. Stahlman MT 1990 Increased survival rate in very low birth weight infants (1500 grams or less): no association with increased incidence of handicaps. J Pediatrics 117: $139-146$

5. Hoffman EL, Bennett FC 1990 Birth weight less than 800 grams: changing outcomes and influences of gender and gestation number. Pediatrics 86: 27-34

6. Ferrara TB. Hockstra RE, Gaziano E. Knox GE, Couser RJ, Fangman JJ 1989 Changing outcome of extremely premature infants $(<26$ weeks gestation and $<750 \mathrm{gm}$ ): survival and follow-up at a tertiary center. Am J Obstet Gynecol 161:1114-1118

7. Pomerance JJ, Schifrin BS. Meredith JL 1980 Womb rent. Am J Obstet Gynecol 187:486-490

8. Fisher DA 1992 Endocrinology of fetal development. In: Wilson JD, Foster DW (eds) Textbook of Endocrinology, 8th Ed. WB Saunders, Philadelphia. pp 1049-1077

9. Burrow GN. Fisher DA. Larsen PR 1993 Maternal and fetal thyroid function. $N$ Engl J Med (in press)

10. Silverman WA 1990 Overtreatment of neonates? A personal perspective. Pediatrics 90:534-537

11. Kleigman RM, Rottman CJ. Behrman RE 1990 Strategies for the prevention of low birth weight. Am J Obstet Gynecol 162:1073-1083

12. Sakamoto $S$, Tokeda $Y$ (eds) 1992 Advances in Perinatal Medicine. Excerpta Medica, Amsterdam. pp 1-13

13. Evans MI, Drugan A. Manning FA. Harrison MR 1989 Fetal surgery in the 1990s. Am J Dis Child 143:1431-1436

14. Bianchi DW, Bernfield M, Nathan DG 1993 A reviewed opportunity for fetal research. Nature 363:12

15. Dostal GH, Gamelli RL 1993 Fetal wound healing. Surg Gynecol Obstet $176: 299-306$

16. Shulman JD 1990 Treatment of the embryo and the fetus in the first trimester: current status and future prospects. Am J Med Genet 35:197-200 